\title{
Suitability of Ambo Sandstone Fine Aggregate as an Alternative River Sand Replacement in Normal Concrete Production
}

\author{
Woyesa Ararsa ${ }^{1}$, Emer Tucay Quezon ${ }^{2, *}$, Abraham Aboneh ${ }^{3}$ \\ ${ }^{1}$ Institute of Technology, Ambo University, Ambo, Ethiopia \\ ${ }^{2}$ Department of Civil Engineering, Institute of Technology, Ambo University, Ambo, Ethiopia \\ ${ }^{3}$ Construction Technology \& Management, Mezan Teppi University, Mezan, Ethiopia \\ *Corresponding author: quezonet09@gmail.com
}

\begin{abstract}
Technical experts in construction industries are trying to improve the quality, ease of using materials in different forms, and increasing structure performance. However, in the changing cost of each item, quality of works could be sacrificed. In Ethiopia, the practice of using alternative ingredients to produce materials was observed weak in some scenarios. It was because ignoring the right procedures to perform the required material requirements for construction materials. It is known that Ambo area has a scarcity of natural sand or rivers sand which can be extracted from the river bed. Notably, if available, the quality is not good due to the presence of silt and clay. Once it used, it adversely affects the structural integrity of concrete structures. The primary objective of the research is to evaluate the suitability of Ambo Sandstone Fine Aggregate (ASFA) as an alternative replacement of river sand in normal concrete production. Samples extracted from Senkele and Aleltu quarry sites of Ambo Area. Results showed that fine aggregates from Senkele quarry site indicated $14.28 \%$ silt content, while from the Aleltu quarry site indicated $12.28 \%$ silt content, all of which exceeded 6\% based on Ethiopian Standard Specification. It means the samples must be rejected or appropriately washed before use as a part of a concrete mix. After performing the procedure to remove silt content, it found out that the silt content reduced to $5.3 \%$, less than the allowable maximum of 6\%. Hence, Ambo Sandstone Fine Aggregates (ASFA) are suitable for concrete mix production and strength determination. There were nine samples of concrete cubes prepared and tested at $7^{\text {th }}, 14^{\text {th }}$, and $28^{\text {th }}$ days for concrete compressive strength with a mix ratio of 1:2:3 and water to cement ratio of 0.50 . Based on the laboratory test results with full replacement of river sand by Ambo Sandstone Fine Aggregate (ASFA), the mean compressive strengths at $7^{\text {th }}$ day was $16.61 \mathrm{MPa}$, while at the $14^{\text {th }}$ day was $19.62 \mathrm{MPa}$, and at $28^{\text {th }}$ day was $25.59 \mathrm{MPa}$. It means at $28^{\text {th }}$ day; it satisfied the minimum requirement for C-25 grade concrete. Likewise, the cost of production of the fine aggregate of the Ambo Sandstone quarry site is 140 ETB per cubic meter, while the price of river sand from Legeher Market is 300 ETB-400 ETB per cubic meter. Therefore, Ambo Sandstone Fine Aggregate (ASFA) is cheaper than the river sand. However, it must be given emphasis that the Ambo Sandstone Fine Aggregates must wash thoroughly before use in construction projects.
\end{abstract}

Keywords: cement, concrete strengths, river sand, sandstone, fine aggregate, production cost

Cite This Article: Woyesa Ararsa, Emer Tucay Quezon, and Abraham Aboneh, "Suitability of Ambo Sandstone Fine Aggregate as an Alternative River Sand Replacement in Normal Concrete Production." American Journal of Civil Engineering and Architecture, vol. 6, no. 4 (2018): 140-146. doi: 10.12691/ajcea-6-4-2.

\section{Introduction}

Quality of construction is the essential aspect under consideration in the construction sector. Sand is one of the principal constituents of concrete making which is about $35 \%$ by volume of concrete used in the construction industry. Properties of aggregates affect the durability and performance of concrete, so fine aggregate is an essential component of concrete. Natural sand is mainly excavated from river beds and always contain a high percentage of inorganic materials, Chlorides, sulfates, Silt and Clay that adversely affect the strength, the durability of concrete and reinforcing steel, hence reducing the life of concrete structures [1].

Increasing extraction of natural sand from river beds causing many problems, losing water retaining sand strata, deepening of the river courses and creating bank slides. Also, it built loss of vegetation on the bank of rivers, exposing the intake well of water supply schemes, disturbs the aquatic life as well as affecting agriculture due to lowering the underground water table, are few examples [2].

The most commonly used in construction is a fine aggregate from river sand or pit sand. Fine and coarse aggregates constitute about $75 \%$ of total concrete by volume. It is, therefore, essential to obtain right type and best quality aggregates at sites, because the aggregate 
forms the main components of the concrete mixture or mortar [3].

In the current situation, the scarcity of natural or river sand has become a problem for the construction industry in Ethiopia. Due to booming construction activities nationwide, natural or river sand resources are increasingly depleted, and at the same time, its cost is increasingly high [4].

Relative to this, searching a source of new substitute of fine aggregate for concrete production, which can be replaced naturally or river sand is significant.

In Ambo area, natural or river sand is rarely available because of its terrain and geographic location, while those available having low quality due to a mixture of sand and clay (i.e., Muddy property). With this kind of problem, the society is forced to look for alternative materials that can replace conventional sand materials which are available in their surroundings. Most people in Ambo area are now using the so-called sandstone sand without checking the quality of the aggregates. Perhaps due to this lack of knowledge on the properties of Ambo Sandstone. One example, a phase- 1 construction projects in the Institute of Technology showed different types of defects on the concrete structures, which prompted the project in-charge to stop the construction. In other words, this construction problem alerted the professionals around the area and tried to think and re-think a proper direction of obtaining construction materials used in every project.

Hence, suitability of replacing natural or river sand with Ambo Sandstone, fine aggregates had been studied to pose an obvious issue by coming up an excellent combination of materials for compressive with reasonable cost. On the other hand, this research will help the community on how to process the sandstone to achieve a good quality of fine aggregate for any concreting works.

Sandstone is a sedimentary rock composed mainly of sand-sized mineral or rock grains. Most sandstone is composed of quartz and or feldspar because these are the most common minerals in earth's crust like sandstone may be of any color. The most common colors are tan, yellow, red, gray and white. Since sandstone beds often form highly visible cliffs and other topographic features, specific colors of sandstone may be strongly identified with particular regions. Sandstones are Calatic in origin (as opposed to organic, like chalk or coal). It formed from the cement grains that may be fragments of a pre-existing rock, or else just mono-mineralic crystals the cement binding these grains together are typically calcite, clays and silica grain size in sands are in the range of 0.1 to $2 \mathrm{~mm}$ [5].

The Ambo sandstone is yellow to red and predominantly fine-grained. The sandstone is quite porous, and therefore easy to split and shape. The color which is reddish at the surface changes into white as the stratification depth continues, the grains are very fine in texture and dusty in dry condition [6].

\section{Stud Area, Materials and Research Methodology}

\subsection{Study Area}

Ambo Town is located around $114 \mathrm{~km}$ west of Addis Ababa. Hence the area named the carved rock after the
Town "Ambo Dingay." In Ambo, the Sandstone is quarried manually from face surface outcrop of a site.

In Ethiopia, the thickest developments of red bed sandstones are within the Triassic successions; it is called the Adigrat sandstone. These are found predominantly in the northern part of the country, but also in central parts, such as the Ambo (i.e., study area), Bure (Gojam) and Abay area. At present, the exploitation of sandstone for building purpose occurs mainly in the Ambo quarries. The abundance of sandstone in Ethiopia is presented in figure 1 of the geological map of Ethiopia [7].

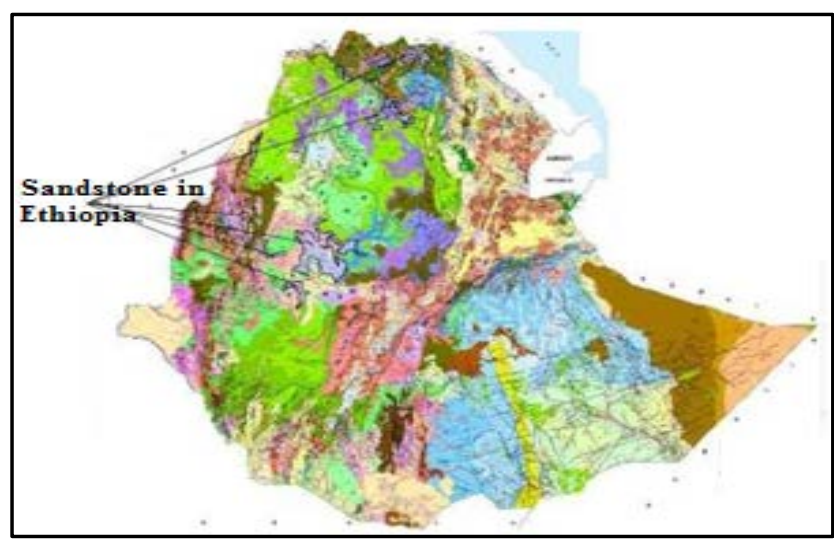

Figure 1. Geological map of Ethiopia [7]

\subsection{Materials}

The materials used for the research described concerning their source and relevant physical properties. All the laboratory investigations on the aggregates and concretes are carried out in the AAiT Construction Laboratory.
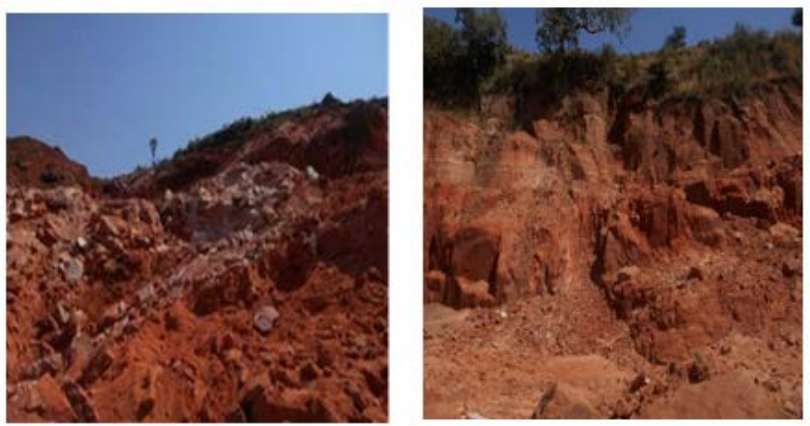

Figure 2a. Aleltu Quarry Site, Ambo Sandstone (Photo taken during ocular inspection)
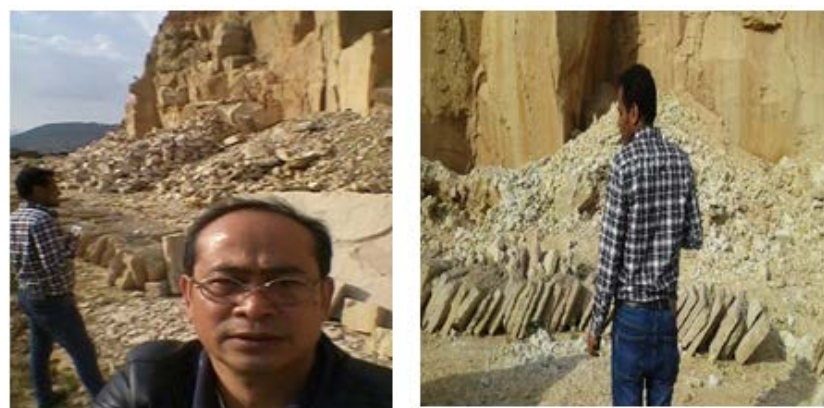

Figure 2b. Senkele Quarry Site, Ambo Sandstone (Photo taken during ocular inspection) 
Ambo Sandstone fine aggregate (ASFA), Ordinary Portland cement, Coarse aggregates, and water were materials components used in this research. These replacement materials (Ambo Sandstone, fine aggregate (ASFA) extracted from Senkele and Aleltu Quarry Sites, which are around 4-km away from the Ambo Town center. The quarry sites are shown in Figure 2.

\section{Source of materials:}

a) Cement- Derba PPC. The product of this cement brand purchased from the shop available in Ambo town.

b) Coarse aggregate- Akaki River, around Bole Airport, Addis Ababa

c) Fine Aggregate (FA) - Ambo Sandstone

d) River Sand - Legeher Market, Addis Ababa

e) Water- In this research, tap water supplied by the Addis Ababa City Water and Sewerage Authority

\subsection{Determining Engineering Property of Materials}

The engineering properties of all materials necessary for describing the type of materials used and also properties that can affect the production of concrete determined before production. The test methods used for the aggregates are listed in Table 1.

Table 1. Property tests and test methods

\begin{tabular}{|l|c|}
\hline \multicolumn{1}{|c|}{ Property Tests } & Test Methods \\
\hline $\begin{array}{l}\text { Sieve analysis (Ambo Sandstone FA, } \\
\text { coarse aggregate) }\end{array}$ & ASTM C-136 \\
\hline $\begin{array}{l}\text { Unit weight (Ambo sandstone FA, coarse } \\
\text { aggregate) }\end{array}$ & ASTM C-29 \\
\hline Silt content (Ambo Sandstone FA) & ASTM C117 \\
\hline $\begin{array}{l}\text { Flakiness index (coarse aggregate) } \\
\text { Specific gravity and absorption (Ambo } \\
\text { Sandstone FA, coarse aggregate) }\end{array}$ & BST 812-105.1: 1989 \\
\hline $\begin{array}{l}\text { Moisture content (Ambo Sandstone FA, } \\
\text { coarse aggregate) }\end{array}$ & part 2:1995 \\
\hline
\end{tabular}

\subsubsection{Sieve Analysis and Fineness Modulus}

The Sieve analysis is a procedure for the determination of the particle size distribution of the aggregate. It is also used to determine the fineness modulus, an index to the fineness, coarseness, and uniformity of aggregates. These properties of the aggregate significantly affect the property of the concrete.
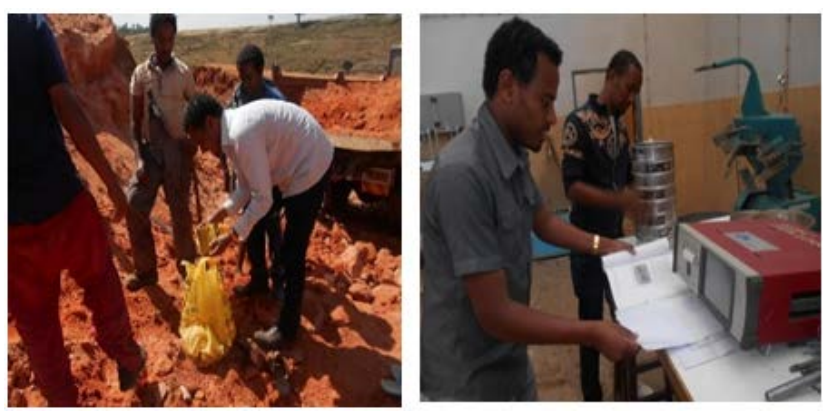

Figure 3. Sampling, Sieve analysis, and fineness modulus determination

\subsubsection{Unit Weight}

The unit weight defined as the weight of a given volume of graded aggregate. It is the density measurement and is also known as bulk density. But this alternative term is similar to bulk specific gravity, which is quite a different quantity, and perhaps is not a good choice. The unit weight efficiently measures the volume that the graded aggregate will occupy in concrete and includes both the solid aggregate particles and the voids between them. The unit weight merely is measured by filling a container of known volume and weighing it. However, the degree of tamping or time vibration will change the amount of void space.

Since the weight of the aggregate is dependent on its moisture content, constant moisture content is required. Oven dried aggregate sample used in this test [8].

The relative bulk density (unit weight) of aggregate commonly used in normal-weight concrete ranges from about 1200 to $1750 \mathrm{~kg} / \mathrm{m} 3$ (75 to $110 \mathrm{lb} / \mathrm{ft} 3$ ) [9].

\subsubsection{Specific Gravity and Absorption Capacity}

Specific gravity is an expression of the density of an aggregate. It is the ratio between the weight of the substance and that of the same volume of water. Aggregates contain pores in their structure. Therefore, the specific gravity depends on whether the pores included in the measurement or not. The apparent specific gravity of an aggregate refers to the solid materials excluding the pores, and bulk specific gravity refers to total volume, i.e., including pores of the aggregate.

\subsubsection{Silt Content}

The material in fine aggregates which is finer than $75 \mu \mathrm{m}$ regarded as silt. Silt content in the sand for the concrete has a severe effect on the quality of the concrete. It mainly affects the workability of the concrete, and also results in the reduction of strength.

\subsubsection{Moisture Content}

The water to cement ratio of concrete affects the strength and the workability of the concrete. The increase of the water to cement ratio results in a decrease of the strength of the concrete and improvement of workability. The aggregates in concrete are assumed to be inert materials. But most of the aggregates do not meet this assumption by either absorbing water (dry aggregates) or by releasing it (wet aggregates) to the mix. As a result of this property of aggregates the design water to cement ratio of the mix changes.

Therefore, it is important to determine both the absorption capacity and the moisture content of the aggregate. The moisture content of fine aggregates was determined by oven drying a sample of fine aggregate $(500 \mathrm{gm})$ in an oven at a temperature of $110^{\circ} \mathrm{C}$ for $24 \mathrm{hrs}$ and dividing the weight difference by the oven dry weight.

\subsubsection{Concrete Mix design}

Mix design is the process of determining the required and specified characteristics of a concrete mixture. The required or specified concrete characteristics can be fresh concrete properties, mechanical properties of the hardened 
concrete such as strength and durability requirements and the inclusion or exclusion of specific ingredient [9].

One of the concrete mix design methods is the ACI method of proportioning is empirical in the sense that it depends on data tabulated from observation of a large number of trial mixtures bearing in mind that the selection of concrete proportions involves a balance between reasonable economy and requirements for place ability, strength, and durability. The quality and durability of standard concrete directly depend on the number and the shape of voids. So, to produce a durable concrete, it is necessary to reduce the amount of air trapped inside the concrete, which conducted by vibrating the concrete in the mixing stage or the casting stage [10].

\subsubsection{Compressive Test and Production Cost Calculation}

Compressive strength test was carried out on the samples prepared to compare the compressive strength of the concrete with full replacement of river sand with Ambo Sandstone fine aggregate. Compressive strength test at 7th, 14th and 28th days conducted according to ASTM 33. For the production cost calculation was performed based on direct unit production costs to compare the production costs from the source of materials.

\subsection{Sample Size and Sampling Procedure}

A purposive sampling selection process utilized in this research. The sample aggregates based on the types of test requirement and standards. For each test, quartering, and weighting used for sampling technique. The output of the laboratory tests compared the strength of normal weight concrete with sandstone fine aggregate and the standard specifications.

There were nine (9) samples of cube size of $150 \mathrm{~mm} * 150 \mathrm{~mm} * 150 \mathrm{~mm}$ mold used for each test of the characteristic compressive strength of concrete based on ASTM 33. The characteristic strength of concrete usually measured by using the compression test machine at different ages of concrete.

\section{Results and Discussion}

\subsection{Physical Properties of Materials}

To specify the type of materials used in this research and to check whether the materials incorporated are recommended by the standards and documents regarding the concrete production, physical properties test of materials conducted.

Table 2. Silt contents of Ambo Sandstone (ASFA)

\begin{tabular}{|l|c|}
\hline Source of Sandstone Fine Aggregate (FA) & Silt content of FA (\%) \\
\hline Senkele Quarry Site & 14.28 \\
\hline Aleltu Quarry Site & 12.28 \\
\hline
\end{tabular}

According to the Ethiopian Standard, it is recommended to wash the sand or reject if the silt content exceeds a value of $6 \%$. Therefore, based on the result as shown in Table 3 silt content of the Ambo Sandstone fine aggregate (FA) from Senkele Quarry Site and Aleltu Quarry Site indicated above the limit of Ethiopian standards. Hence, washing drying-sieve were undertaken.

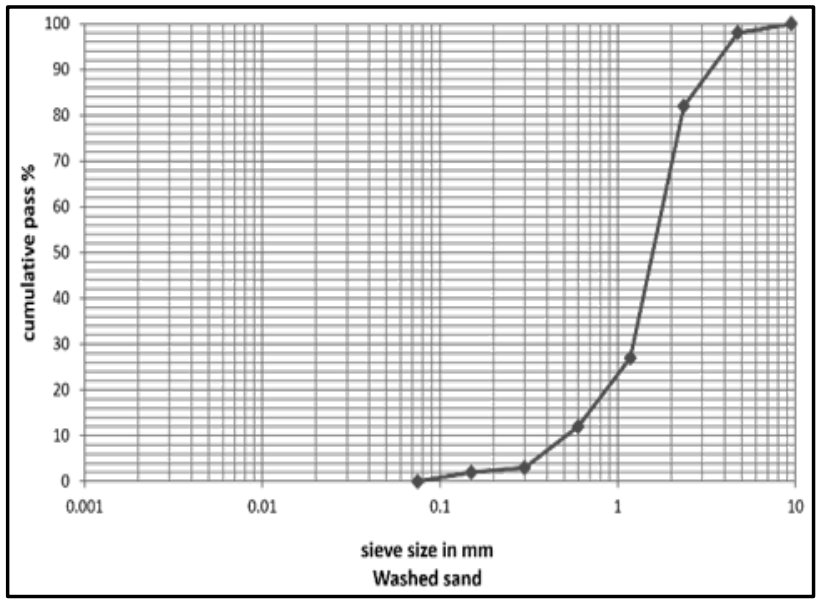

Figure 4. Gradation Curve

After performing the procedure, the Silt content of Ambo Sandstone, fine aggregate (FA) showed 5.3\% which was less than the allowable $6 \%$.

\subsection{Gradation, Bulk Density, Specific Gravity and Fineness Tests on Fine Aggregates}

The purpose of this study was to conduct a systematic comparison of the effects of fine aggregate (FA) exerted on compressive strength. The ASFA was taken from Ambo Sandstone quarry sites.

\subsubsection{Sieve Analysis}

In Table 3 shows the percent passing of Ambo Sandstone fine aggregate (ASFA) from two quarry sites (i.e., Senkele \& Aleltu Quarry sites).

Table 3. Sieve Analysis Comparison after washing

\begin{tabular}{|c|c|c|c|c|}
\hline $\begin{array}{c}\text { Sieve size } \\
(\mathrm{mm})\end{array}$ & $\begin{array}{c}\text { Standard } \\
\text { No. of } \\
\text { Sieve }\end{array}$ & $\begin{array}{c}\text { \% Pass } \\
\text { (Senkele } \\
\text { Quarry Site) }\end{array}$ & $\begin{array}{c}\text { \% Pass } \\
\text { (Aleltu } \\
\text { Quarry Site) }\end{array}$ & $\begin{array}{c}\text { Gradation } \\
\text { Req’t ASTM } \\
\text { (C33- 03) }\end{array}$ \\
\hline 9.5 & $3 / 8 ”$ & 96.2 & 100 & 100 \\
\hline 4.75 & No. 4 & 91 & 98.4 & $95-100$ \\
\hline 2.36 & No. 8 & 86.4 & 95.8 & $80-100$ \\
\hline 1.18 & No. 16 & 77.4 & 86.6 & $50-85$ \\
\hline 0.6 & No. 30 & 40 & 50.8 & $25-60$ \\
\hline 0.3 & No. 50 & 11.8 & 15.2 & $10-30$ \\
\hline 0.15 & No.100 & 3 & 4.4 & $2-10$ \\
\hline 0.075 & No. 200 & 0.2 & 0.8 & - \\
\hline 0 & Pan & 0 & 0 & \\
\hline
\end{tabular}

The result of sieve analysis indicated that Sieve No.4, the ASFA from Senkele quarry site was slightly below the minimum grading requirement of 95\%. Similarly, Sieve No. 16, the ASFA from Aleltu quarry site was slightly higher than the maximum range of $85 \%$. It means the Sandstone FA from Aleltu quarry site is Coarser particle sizes than the materials from Senkele quarry site. 


\subsubsection{Fineness Modulus}

A factor obtained by adding the total percentages of material in the sample that are coarser aggregate than each of the following sieves (cumulative percentages retained), and dividing the sum by 100 :

Table 4. Sieve Analysis in Cumulative (\%) Retained

\begin{tabular}{|c|c|c|c|c|}
\hline $\begin{array}{c}\text { Sieve } \\
\text { size } \\
(\mathrm{mm})\end{array}$ & $\begin{array}{c}\text { Senkele } \\
\text { (\% retained) }\end{array}$ & $\begin{array}{c}\text { Aleltu } \\
\text { (\% retained) }\end{array}$ & $\begin{array}{c}\text { Senkele } \\
\text { (Cum \% } \\
\text { retained) }\end{array}$ & $\begin{array}{c}\text { Aleltu } \\
\text { (Cum \% } \\
\text { retained) }\end{array}$ \\
\hline 9.5 & 3.8 & 0 & 0 & 0 \\
\hline 4.75 & 5.2 & 1.6 & 8.8 & 1.6 \\
\hline 2.36 & 4.6 & 2.6 & 13.64 & 4.2 \\
\hline 1.18 & 9 & 9.2 & 22.4 & 13.4 \\
\hline 0.6 & 37.4 & 35.8 & 59.8 & 49.2 \\
\hline 0.3 & 28.4 & 35.6 & 88.2 & 84.8 \\
\hline 0.15 & 8.8 & 10.8 & 97 & 95.6 \\
\hline 0.075 & 2.8 & 3.6 & 99.8 & 99.2 \\
\hline pan & 0.2 & 0.8 & 100 & 100 \\
\hline
\end{tabular}

Ambo Sandstone Fine Aggregates (ASFA), Fineness modulus calculation:

$$
\begin{aligned}
& \text { Senkele } F A=\left(\begin{array}{l}
8.8+13.64+22.4 \\
+59.8+88.2+97
\end{array}\right) / 100 \\
& =289.84 / 100=2.89
\end{aligned}
$$

Aleltu FA $=\left(\begin{array}{l}1.6+4.2+13.4 \\ +49.2+84.8+95.6\end{array}\right) / 100=248 / 100=2.48$

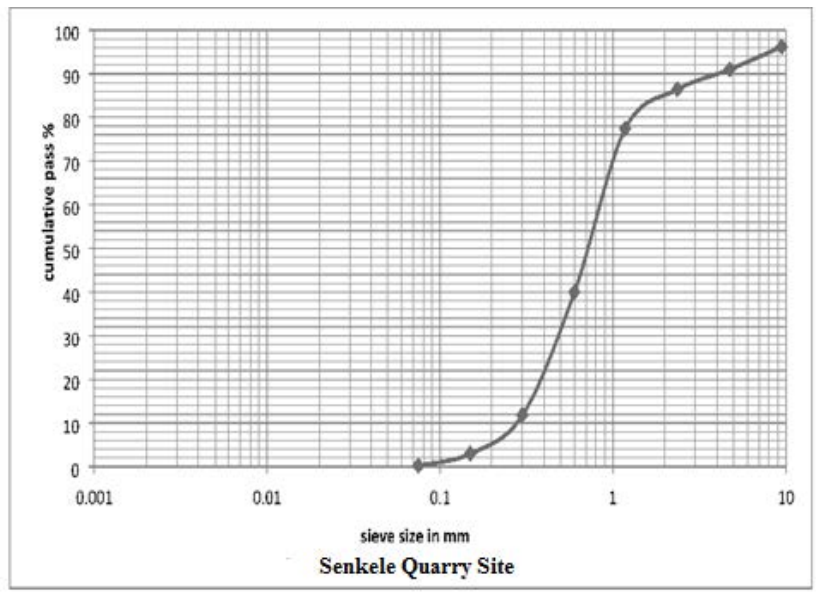

Figure 5. Senkele ASFA Particle size distribution graph

In Figure 5, it shows the particle size distribution curve, Ambo Sandstone Fine Aggregate (Senkele ASFA) possessed proper grading but with large size particles which were under the limit. According to ASTM C33-03, the fine aggregate should not be more than $45 \%$ passing in any sieve and retained on the next consecutive sieves, while its fineness modulus should not be less than 2.3 and not be more than 3.1.

Based on the results, the fineness modulus of Ambo sandstone fine aggregate from Senkele quarry site indicated 2.89, while the fine aggregate from the Aleltu quarry site indicated 2.48. It means both fine aggregates are well-graded representing workable concrete mixes.
Table 5. Specific Gravity, Moisture Content \& water Absorption

\begin{tabular}{|c|l|c|c|}
\hline \multicolumn{2}{|c|}{ Other Laboratory Test Results } & $\begin{array}{c}\text { Senkele } \\
\text { quarry FA }\end{array}$ & $\begin{array}{c}\text { Aleltu } \\
\text { quarry FA }\end{array}$ \\
\hline $\mathbf{1}$ & Surface Dry Specific Gravity $\left(\mathrm{g} / \mathrm{cm}^{3}\right)$ & 2.54 & 2.56 \\
\hline $\mathbf{2}$ & Bulk Specific Gravity $\left(\mathrm{g} / \mathrm{cm}^{3}\right)$ & 2.50 & 2.52 \\
\hline $\mathbf{3}$ & Moisture Content (\%) & 2.88 & 3.52 \\
\hline $\mathbf{4}$ & Apparent Gravity (g/cm $\left.{ }^{3}\right)$ & 2.60 & 2.64 \\
\hline $\mathbf{5}$ & Water Absorption (\%) & 1.42 & 1.83 \\
\hline
\end{tabular}

Coarse Aggregates:

Samples of crushed coarse aggregates bought from the Legeher market, originally quarried from Akaki quarry site, Addis Ababa.

Table 6. Sieve Analysis of coarse crushed aggregate

\begin{tabular}{|c|c|c|c|}
\hline No. & $\begin{array}{c}\text { Sieve size } \\
(\mathrm{mm})\end{array}$ & $\begin{array}{c}\text { Crushed Coarse } \\
\text { aggregate } \\
\text { (\% passing) }\end{array}$ & $\begin{array}{c}\text { Grading requirement, } \\
\text { (ASTM C-33) } \\
\text { (\% passing) }\end{array}$ \\
\hline 1 & 75 & - & - \\
\hline 2 & 37.5 & 100 & $90-100$ \\
\hline 3 & 25 & 94 & $20-55$ \\
\hline 4 & 19 & 44 & $0-10$ \\
\hline 5 & 12.5 & 9 & $0-5$ \\
\hline 6 & 9.5 & 1 & \\
\hline
\end{tabular}

Coarse aggregates consisted of crushed stone with particles predominantly larger than $9.5 \mathrm{~mm}$ and generally between $9.5 \mathrm{~mm}$ and $37.5 \mathrm{~mm}$ are readily used in the concrete mix after minimal processing.

\subsection{Concrete Mix Design}

ACI method of mix design used in designing the concrete mixes. The trial mix prepared for the particular strength of C-25 grade concrete or $25 \mathrm{MPa}$ compressive strength. The water to cement ratio used 0.50 , and a cement content of $355.5 \mathrm{~kg} / \mathrm{m} 3$, while the maximum size of aggregates used $20 \mathrm{~mm}$. The trial mix resulted in a slump of $47 \mathrm{~mm}$. While in the actual concrete mixed for samples, the maximum coarse aggregate size was $37.5 \mathrm{~mm}$. The mix design, proportion to $100 \%$ Ambo Sandstone, fine aggregates (ASFA) from the Aleltu Quarry Site as a full replacement of river sand prepared with a ratio of $1: 2: 3$.

\subsection{Experimental Tests on Compressive Strength}

In this experimental investigation, the strength characteristics of concrete determined using Ambo Sandstone Fine Aggregate (ASFA) for C-25 grade concrete. The ASFA has fully replaced the river sand. Concrete cubes were cast and tested on the 7 th day, $14^{\text {th }}$ day and $28^{\text {th }}$ day after the curing period.

\subsubsection{Test of Compressive Strength}

To obtain the compressive strength, nine cubes were cast and tested on the 7 th day, $14^{\text {th }}$ day and $28^{\text {th }}$ day age. The results are shown in Table 7. 
Table 7. Compressive Strengths at different curing period

\begin{tabular}{|c|c|c|c|c|}
\hline 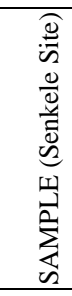 & 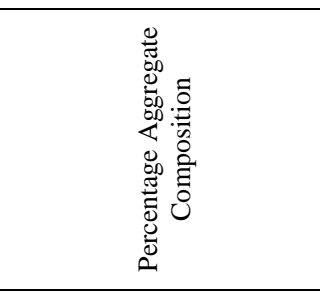 & 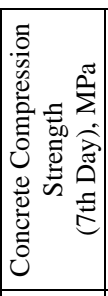 & 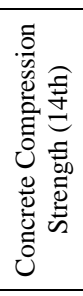 & 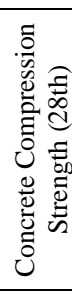 \\
\hline 1 & 100\% Ambo Sandstone-FA & 17.03 & 20.08 & 26.20 \\
\hline 2 & 100\% Ambo Sandstone-FA & 16.64 & 19.70 & 25.60 \\
\hline 3 & 100\% Ambo Sandstone-FA & 16.18 & 19.09 & 24.90 \\
\hline \multicolumn{2}{|c|}{ Average Compressive Strength, (MPa) } & 16.61 & 19.62 & 25.60 \\
\hline
\end{tabular}

Based on the test results, the mean strength was described at $7^{\text {th }}$ day, $14^{\text {th }}$ day and $28^{\text {th }}$-day curing period. The highest recorded compressive strength at $7^{\text {th }}$ day was 17.03 MPa among the three samples tested, with a mean compressive strength of $16.61 \mathrm{MPa}$. Likewise, at the 14th day curing period, the highest recorded compressive strength was $20.08 \mathrm{MPa}$, while the mean compressive strength was $19.62 \mathrm{MPa}$. On $28^{\text {th }}$ day curing period, the highest recorded was $26.20 \mathrm{MPa}$ for sample 1 . The average compressive strength obtained 25.60 MPa. From $7^{\text {th }}$ day up to $28^{\text {th }}$-day curing period, it implied that as the curing period increases, the compressive strength also increases. This is true for C-25 grade concrete strength in this experiment.

Therefore, at the 28th day curing period, the samples meet the minimum required strength for $\mathrm{C}-25$ grade concrete. It must be given emphasis that the Ambo Sandstone Fine Aggregate (ASFA) was adequately washed to remove silt contents and dirt impurities.

\subsection{Cost Analysis}

Aggregates production in Ethiopia has been and will continue to be a local business based on readily accessible natural deposits. Most of the quarry sites are owned by the local farmers on private land. They sell their products or lease the quarry sites to contractors for different construction works.

In Ambo area, there are several types of quarry sites can be found. One of which is Senkele Quarry site wherein Ambo Sandstone Fine Aggregate (ASFA) is located. Another one is Aleltu Quarry site. The same type of materials like Ambo Sandstone Fine Aggregate can be taken. However, the process of extracting the fine aggregates from these sites provides the cheapest cost of materials as compared with the river sand. In other words, the true cost of aggregate material is influenced by various factors such as production and transportation costs play a major role.

\subsubsection{Production Costs}

From the source, the average production cost of the fine aggregate at Ziway area (quarry site near Hawassa) is 135 Birr $/ \mathrm{m}^{3}$ including VAT, while Ambo Sandstone Fine Aggregate is $140 \mathrm{Birr} / \mathrm{m}^{3}$ at Aleltu Quarry Site and 120Birr/m3 at Senkele Quarry Site including VAT.

\subsubsection{Transportation Costs}

Based on the Contractor's record who is currently constructing building projects in Ambo University
Institute of Technology campus, the transportation cost to bring Ambo Sandstone Fine Aggregates from Aleltu Quarry Site to University construction site ranges from 1000 Birr -1200 Birr per Sino truck (16 $\mathrm{m}^{3}$ Capacity). The construction site is around $7 \mathrm{kms}$ distance from Aleltu site. On the other hand, considering Ambo center, which is around $4 \mathrm{~km}$ away from the Aleltu sand production site, the transportation cost per Sino truck ranges from 900 Birr-1000 Birr.

Table 8. Distribution Cost per $\mathrm{m} 3$ of fine aggregates in Addis Ababa and Ambo (without transportation cost).

\begin{tabular}{|c|c|c|c|}
\hline Sand type & Cost per $\mathrm{m}^{3}$ & $\begin{array}{c}\text { One Sino truck } \\
\left(16 \mathrm{~m}^{3}\right) \\
\text { Pick-up Price }\end{array}$ & Location \\
\hline $\begin{array}{c}\text { Ambo } \\
\text { Sandstone Fine } \\
\text { Aggregate } \\
\text { (ASFA) }\end{array}$ & 140 ETB & 2240 ETB & $\begin{array}{c}\text { Ambo } \\
\text { (quarry } \\
\text { site) }\end{array}$ \\
\hline $\begin{array}{c}\text { River Sand } \\
\text { (originally from } \\
\text { Ziway Area) }\end{array}$ & $\begin{array}{c}300-400 \mathrm{ETB} \\
\text { (at site) }\end{array}$ & $7500-8000$ ETB & $\begin{array}{c}\text { Legeher } \\
\text { Market }\end{array}$ \\
\hline
\end{tabular}

Table 8 is generated from the fact that from Addis Ababa to Ambo is approximately equal to $114 \mathrm{~km}$ distance from the Ambo Sandstone quarry site. As, is observed from the table, Ambo Sandstone Fine Aggregate (ASFA) has a relative economical advantage over river sand once; it will be used for construction projects around Addis Ababa.

Similarly, for construction projects around Ambo area, Ambo Sandstone Fine Aggregate (ASMA) cost is fair since the quarry site available at $3 \mathrm{kms}$ outside the town center, which is less regarding transportation cost, and even to the minimum price level.

\section{Conclusion}

The experimental works in the laboratory to evaluate the fresh and hardened properties of full replacement of river sand with Ambo Sandstone Fine Aggregates (ASFA) has been carried out. Based on the findings of the laboratory test results; the conclusions are drawn:

- The silt contents of Ambo Sandstone Fine Aggregates (ASFA) from Senkele and Aleltu quarry sites indicated $14.28 \%$ and $12.28 \%$, respectively. Based on Ethiopian standard, a silt content exceeds $6 \%$, the sand would be washed or rejected as a part of the concrete. Hence, after performing the procedure to remove silt content, it was found out that the silt content reduced to $5.3 \%$, less than the allowable maximum of $6 \%$. Therefore, Ambo Sandstone Fine Aggregate (ASFA) is suitable for concrete mix production and strength determination.

- Both samples from Ambo Sandstone quarry sites are well graded, although sieve \#4, the percent passing from Senkele indicated slightly lower the minimum range based on the grading requirements of ASTM C33-03). While the percent passing of sample from Aleltu, for sieve \#16 indicated slightly higher the range per grading requirements. Therefore, there is no significant effect on the compressive strength of concrete production. 
- The Fineness Modulus of samples from Senkele and Aleltu Quarry sites indicated 2.89 and 2.48, respectively. The values are within the range of 2.3 to 3.1 per standard specification. It is well graded and provides workable concrete mixes. Therefore, Ambo Sandstone Fine Aggregate (ASFA) is suitable for normal concrete production.

- The mean compressive strengths at $7^{\text {th }}$ day, $14^{\text {th }}$ day, and $28^{\text {th }}$ day indicated 16.61 MPa, 19.62 $\mathrm{MPa}$, and 25.60 MPa, respectively. Based on this laboratory test results, at $28^{\text {th }}$ day curing period for Ambo Sandstone Fine Aggregates (ASFA) attained the minimum required strengths for $\mathrm{C}-25$ grade concrete.

- On the other hand, the production cost at quarry sites (i.e., Pick-up price), Ambo Sandstone Fine Aggregate (ASFA) is cheaper than the price per cubic meter of river sand by $114.28 \%$.

To sum up, Ambo Sandstone Fine Aggregates (ASFA) fits the standard specifications with all laboratory test results except silt and clay contents. Therefore, before using it in a concrete mix, it must be washed thoroughly which can be served as a suitable replacement for river sand.

\section{References}

[1] Partial Replacement of M-Sand on Concrete by Self Curing and Standard Curing Method. N.R.Monika1, S.Sarankokila2. Issue 12, Tamilnadu, India: International Journal of Innovative Research in Science, Engineering, and Technology, December 2015, Vol. 4.

[2] Effect of replacement of natural sand by manufactured sand on the properties of cement mortar. Priyanka A. Jadhav, Dilip K. Kulkarni. Bombay, Maharashtra, India: International Journal of Civil and Structural Engineering, 2013, Vol. Volume 3. ISSN 0976-4399.

[3] Manufactured sand for concrete. B.P., Hudson. S.l. : The Indian Concrete Journal, 1997, pp. Pp 237-240.
[4] The use of manufactured sand in concrete production, test result, and cost comparison. Dinku, Shewaferaw. Addis Ababa: s.n., 2006.

[5] Mengistu, T. and Fentaw, H.M., Industrial Minerals and Rocks Resource Potential of Ethiopia, FDRE Ministry of Mines, Geological Survey of Ethiopia, March 2003

[6] Sintayehu Zewudie, Opportunities for dimension stone resource development in Ethiopia, Addis Ababa, 2011

[7] Newill, D. and Kassaye Aklilu, The location and engineering properties of volcanic cinder gravels in Ethiopia, 7th Regional Conference for Africa on Soil Mechanics and Foundation Engineering, Accra, Ghana, 1-7 June 1980,

[8] Dinku, Abebe. Construction Materials Laboratory Manual. Addis Ababa: Addis Ababa University Printing Press, June 2002.

[9] Steven Kosmatka H., Beatrix Kerkhoff, and William Panarese C. Design and Control of Concrete Mixtures, 14th edition, 2003. Pp. 149-160.

[10] Emer Tucay Quezon, et.al. A Study on the Effect of Time Duration by Vibrating or Tamping Fresh Concrete on the Compressive Strength of C-25 Concrete. American Journal of Applied Scientific Research. Vol. 3, No. 6, 2017, pp. $72-79$.

[11] Effect of high levels of fines content of concrete properties. Amnon K., and Hadassa B. S.l. : ACI Material Journal, 2006, Pp 474-481.

[12] Experimental investigation on the effect of M-Sand in highperformance concrete. Adams Joe, A. Maria Rajesh, P. Brightson. M. M. Prem. Anand. America: American Journal of Engineering Research (AJER), 2013, pp. 46.

[13] Effects of partial replacement of natural sand with crushed sand along with supplementary cementing materials fly Ash and GGBS. Karan Verma, P.S Pajgad. S.l. : International Journal of Engineering Technology, 2015.

[14] Comparative Study of Cost Analysis, Strength of Concrete with Natural and Manufactured sand in Residential Building. Vaidya, Bhishma K. S.l. : International Journal on Recent and Innovation Trends in Computing and Communication, 2015, Vol. Vol. 3.

[15] Experimental Investigation On The Strength Characteristics of Concrete Using Manufactured Sand. Vijaya. B, Felix Kala. T., Senthil Selvan. S, R. Annadurai. Issue 8, Chennai, India. : IJIRST -International Journal for Innovative Research in Science \& Technology, January 2015, Vol. Volume 1. ISSN (online): 23496010.

[16] Committee, ACI. Guide for Measuring, Mixing, Transporting, and Placing Concrete. America: America concrete institute, 2000. 